\title{
APLICANDO O QUADRO DE REFERÊNCIA PARA ANÁLISE JURÍDICA DE POLÍTICAS PÚBLICAS: A IMPLEMENTAÇÃO DO \\ PROGRAMA MINHA CASA, MINHA VIDA, FAIXA 1, NO MUNICÍPIO DE SÃO PAULO
}

\section{USING THE PUBLIC POLICY LEGAL ANALYSIS FRAMEWORK: THE IMPLEMENTATION OF MINHA CASA, MINHA VIDA, FAIXA 1, IN THE CITY OF SÃO PAULO}

MARCELO CHILVARQUER ${ }^{1}$

Resumo: Um importante desafio da abordagem de Direito e Políticas Públicas (DPP) é a dificuldade de desenvolver um método que garanta a identificação do objeto de estudo, viabilizando sua comparabilidade. Para responder a essa situação, formulou-se o "Quadro de Referência para Análise Jurídica de Políticas Públicas" (BUCCI, 2015), que articulou de maneira sistemática os elementos mais importantes a serem examinados em uma pesquisa da abordagem. Pretende-se apresentar nesse artigo um exemplo de sua aplicação na implementação do Programa Minha Casa, Minha Vida (MCMV) Faixa 1 no Município de São Paulo. Após a introdução, o artigo será dividido em 4 partes. Na primeira, mais teórica, serão apresentados os desafios da utilização do quadro em uma política tão complexa como o MCMV, implementado em centenas de municípios. Na segunda, será apresentado o desenho geral do programa formulado nacionalmente, em que se definem papéis institucionais na política. Na terceira parte se analisará a implementação do MCMV Faixa 1 no município. Por fim, a última parte destacará os principais entraves e inovações que a política pública teve em sua implementação, enfocando quais ferramentas jurídicas foram mobilizadas para sua solução, além de se fazer uma análise crítica sobre o atingimento das finalidades pretendidas com a ação.

Palavras-Chave: . Abordagem Direito e Políticas Públicas; Quadro de Referência para Análise Jurídica de Políticas Públicas; Implementação de políticas públicas; Minha Casa, Minha Vida Faixa 1.

\footnotetext{
${ }^{1} \mathrm{O}$ autor é Mestre em Direito Econômico pela USP. Além de sua experiência acadêmica, o autor trabalhou na Administração Pública, destacando-se o período em que foi assessor do Secretário de Assuntos Legislativos (SAL) do Ministério da Justiça e Chefe do setor jurídico da empresa pública municipal de desenvolvimento urbano, SP-Urbanismo. Contato: marcelochil@gmail.com. Lattes: http://lattes.cnpq.br/0011352520580545.
} 
Abstract: One of the main challenges of the Law and Public Policy approach is to develop a method that allows comparability between researches that analyses government action in all its complexity. A methodological response to this problem is the use of a "Public Policy Legal Analysis Framework" that organizes in a systematic way the main elements that should be analysed by legal scholars when studying a public policy. This paper will present an example of that framework's use when analyzing the implementation of the main housing policy program in Brazil, Minha Casa, Minha Vida's (MCMV), in the city of São Paulo, most specifically the subprograms aimed at the lowest income demographic (Faixa 1 range). This paper will be divided in four parts after introduction. The first one, more theoretical, focuses on the main challenges of using the framework when analyzing a complex policy like MCMV that has its main rules determined at the federal level but is implemented in thousands of cities at the municipal level. The second one presents the program main rules which are stablished by the federal government. The third one presents data on the implementation of MCMV in São Paulo. The final part of the paper sheds light to the difficulties and innovations that derived from the implementation of a federal housing program in the municipal level focusing on the juridical tools used to overcome these constraints and also providing a critical analysis of the MCMV's outcomes.

Keywords: Law and Public Policy approach; Public Policy Legal Analysis Framework; Public policy implementation.

\section{INTRODUÇÃO}

O estudo de uma política pública ${ }^{2}$ é por essência uma empreitada interdisciplinar. Desde a delimitação do problema público que objetiva ser solucionado com a ação governamental, passando pela análise de capacidade das instituições que irão implementar a política até a disponibilidade orçamentário-

\footnotetext{
2 Ao longo de todo o texto, a expressão "política pública" será constantemente utilizada. Para facilitar a compreensão do leitor, estabelece-se, a partir desse momento, que sua definição nesse texto será a dada por Bucci (2013): “política pública é o programa de ação governamental que resulta de um processo ou conjunto de processos juridicamente regulados". Como se vê, para fins desse artigo, considerarei como premissa que o conceito de política pública pressupõe uma ação estatal, ainda que reconheça o fato de que há diversos acadêmicos, especialmente na ciência política, que defendam visão distinta, ou seja, de que há políticas públicas que não pressupõem atuação do Estado como fator central.
} 
financeira para sua execução, há uma miríade de enfoques possíveis quando se trata desse tipo de investigação.

A abordagem DPP (BUCCI, 2019) objetiva, no mínimo (sem qualquer pretensão de ser exaustivo nesse rol), sistematizar uma intersecção de conhecimentos que leva em conta elementos de direito, política, economia e gestão pública. É, no limite, o reconhecimento de que esse tipo de abordagem não é nem uma área "exclusiva" do jurista nem um meio interditado a ele, mas sim parte de um espaço acadêmico coletivo e multidisciplinar ${ }^{3}$ em que diversas áreas do conhecimento devem colaborar para a construção de uma massa crítica sobre determinada política pública.

De outra parte, é também necessário reconhecer que dentre as diversas características do direito em relação às políticas públicas, a neutralidade definitivamente não é uma delas (COUTINHO, 2013b). É por meio do direito que se determinam pontos de chegada para as ações governamentais (i.e. reduzir a pobreza, combater o déficit habitacional). São ferramentas juridicamente determinadas que podem facilitar ou dificultar uma medida governamental (i.e. isenções tributárias, subsídio habitacional) e são normas do direito que determinam quem faz o quêt (i.e. União, Estados e municípios, quais tipos de empresas) na implementação de determinada política pública.

Apesar dessa importância, tem sido um desafio ${ }^{5}$ para os juristas desenvolver um método estruturado que possa garantir comparabilidade ao conjunto de estudos jurídicos sobre determinada política pública (BUCCI, 2015).

A existência de tal método, presume-se, poderia implicar a construção de uma massa crítica sobre as ações governamentais estudadas e, portanto, possibilitaria uma melhor capacidade de intervenção nelas por meio do direito facilitando a resolução de problemas e a superação de gargalos na sua execução.

Diante deste problema, Maria Paula Dallari Bucci propôs um quadro de referência para análise jurídica de políticas públicas que contém 12 elementos ${ }^{6}$ que sintetizam os traços mais importantes da política pública.

\footnotetext{
3 Adota-se o conceito de Marques e Faria (2013), que considera multidisciplinar a empreitada acadêmica em que campos disciplinares dialogam, mantendo seus limites originais.

${ }^{4}$ Também chamado em ocasiões passadas por Bucci (2016) de arranjo jurídico-institucional e por Coutinho (2013b) de arranjo institucional, os autores realizaram um artigo sobre o tema em coautoria em 2017.

${ }^{5}$ É fato que esse papel funcional do direito nas políticas públicas tem sido constantemente ignorado pelos juristas brasileiros que comumente preferem realizar pesquisas de caráter mais descritivo de normas e do "estado da arte" na jurisprudência pátria (COUTINHO, 2013b).

6 1) Nome oficial do programa de ação; 2) gestão governamental 3) base normativa; 4) desenho jurídico institucional; 5) Agentes governamentais; 6) Agentes não governamentais; 7) mecanismos jurídicos de articulação; 8) escala e público-alvo; 9) dimensão econômico-financeira do programa; 10) estratégia de implantação; 11) funcionamento efetivo do programa; e 12) aspectos críticos do desenho jurídico-institucional.
} 
O objetivo desse artigo é realizar uma espécie de "teste" do referido quadro a partir da análise de implementação de uma ação governamental em específico: a implementação do Programa Minha Casa, Minha Vida (MCMV) Faixa $1^{7}$ no município de São Paulo ocorrida entre 2009 e $2018^{8}$.

Nesse sentido, serão apresentados os desafios da utilização do método aplicado a uma análise concreta de política pública. O propósito dessa tarefa é contribuir para o desenvolvimento da abordagem DPP indicando os ganhos analíticos e dificuldades da utilização do método para outros pesquisadores no campo do direito.

No que se refere ao conteúdo apresentado sobre o MCMV Faixa 1, quase a sua totalidade é decorrente da pesquisa feita ao longo da dissertação de mestrado deste autor com o título "A implementação do Programa Minha Casa, Minha Vida Faixa 1 no Município de São Paulo" (CHILVARQUER, 2018).

\section{OS GANHOS ANALÍTICOS E DESAFIOS DO USO DO QUADRO DE REFERÊNCIA DA ANÁLISE JURÍDICA DE POLÍTICAS PÚBLICAS NO ESTUDO DE UM CASO CONCRETO}

Conforme apontado por Bucci (2013), a utilização de estudos de caso pelos juristas que querem utilizar a abordagem DPP deve ser feita com um rigor acadêmico tal que possibilite a comparabilidade com futuro trabalhos de pesquisa sobre o mesmo tema. Para tal, um dos elementos centrais é a capacidade de isolar variáveis analisadas que, por sua vez, poderão ser compreendidas como fatores de correlação com o sucesso ou insucesso de determinada ação governamental (BUCCI, 2019).

O exercício de enquadramento da análise da implementação do MCMV Faixa 1 no município de São Paulo nas diretrizes do quadro de referência foi em geral

\footnotetext{
${ }^{7}$ Conforme se verá mais a frente, esse artigo trata exclusivamente da Faixa 1 do programa MCMV destinado a cidades com mais de 50 mil habitantes, ou seja, das modalidades da política destinadas ao público-alvo de menor renda (de zero a três salários mínimos de renda mensal por família). Isso é relevante de se entender, pois, apesar de estar sob a mesma denominação, o MCMV identifica mais uma marca do que uma política pública uniforme, na medida em que suas modalidades têm objetivos, públicos-alvo, fontes de financiamento e atores distintos em sua fase de implementação (CHILVARQUER, 2018, p. 26-29). Devido ao reduzido espaço desse artigo não apresentarei os contornos gerais das outras Faixas.

${ }^{8}$ A limitação temporal decorre de um elemento que será tratado no decorrer do artigo: o MCMV Faixa 1 (objeto desse estudo) é quase que integralmente dependente de subsídios do Tesouro Nacional. A crise econômica por que o Brasil passa desde 2015 fez com que os níveis de contratação desta Faixa fossem sendo reduzidos continuamente até sua virtual paralisação (incluindo cancelamentos de contratações anteriormente previstas) em 2018 (LIS, 2019). A própria Caixa Econômica Federal, em seu site, parou de atualizar os dados do MCMV Faixa 1 a partir de março de 2018.
} 
bastante positivo. Isso ocorreu, pois o método serve como um útil roteiro de questões $^{9}$ a serem respondidas pelo jurista na elaboração de uma pesquisa sobre determinada política pública, ainda que essa seja mutável (i.e. mudanças de governo que implementa a ação, disponibilidade de recursos ao longo do tempo).

Não se deve, entretanto, pressupor que a utilização do quadro de referência é isenta de desafios ao pesquisador do campo do direito. Passa-se a abordar algumas dessas dificuldades com que o acadêmico pode se deparar. Longe de reduzir a relevância do método, o que se objetiva indicar com esses apontamentos é que sua utilização exige algum grau de adaptabilidade do pesquisador para que ele percorra todos os quesitos do quadro sem perder clareza na sua apresentação.

O primeiro desafio, de caráter mais estilístico, é que é relativamente difícil mostrar as respostas dos 12 elementos do quadro de maneira separada (como ele é apresentado) sem perder o encadeamento do texto ou correndo o risco de incorrer em repetições desnecessárias.

Para ilustrar esse ponto utilizando o caso do MCMV Faixa 1, indicam-se duas situações em que é difícil o enquadramento em apenas um dos elementos independentes do quadro. O primeiro é o "desenho jurídico-institucional" do programa que acaba se confundindo, em grande medida, com a apresentação dos papéis dos "agentes governamentais" e "agentes não-governamentais" na sua execução. Além disso, no caso do MCMV, a "estratégia de implantação" está intrinsecamente relacionada com a "escala e público-alvo" do programa.

Há, em outros casos, ganho de clareza para o trabalho acadêmico quando se separa o conteúdo de um mesmo elemento do quadro de referência em partes distintas do texto. Nesse artigo encontra-se um exemplo dessa situação. A apresentação completa do arranjo jurídico-institucional da implementação do MCMV Faixa 1 no município de São Paulo só é exaustivamente explorada se analisarmos quem faz o quê tanto no desenho geral do programa (concebido pela União), como na implementação local (dependente da organização da administração pública municipal). Porém, para fins didáticos, optou-se por seguir o mesmo modelo utilizado na dissertação de mestrado que deu origem a esse artigo e se segmentou o desenho geral federal da implementação local municipal.

De um ponto de vista material, a explicação sobre pontos como a "estratégia de implantação", "funcionamento efetivo do programa" e "aspectos críticos do desenho jurídico-institucional" implica um outro tipo de dificuldade ao pesquisador. Seja porque no Brasil ainda é gritante a ausência de dados estruturados ou até mesmo informações simples sobre a implementação das políticas, seja pelo caráter mais subjetivo do que significa, por exemplo, "funcionamento efetivo" de uma ação governamental, é imperativo que o jurista

\footnotetext{
${ }^{9}$ Ressalva-se aqui, entretanto, que é conhecida por esse autor a dificuldade de utilização do quadro de referência para todas as análises jurídicas de políticas públicas. Um exemplo dessa limitação é o caso da insuficiência do referido instrumento para a investigação de programas não estruturados ou ainda em estruturação (RUIZ; BUCCI, 2019).
} 
tenha em mente que a abordagem DPP não é uma ciência exata e que as conclusões sobre seu objeto de estudo possuirão necessariamente algum grau de questionamento apesar da utilização de métodos como o quadro de referência.

A partir de agora, passa-se à aplicação do método na análise da implementação do MCMV Faixa 1 no Município de São Paulo, iniciando pela apresentação geral do desenho do programa e depois passando para aspectos da implementação local.

\section{ORIGEM E DESENHO FEDERAL DO MCMV FAIXA 1}

\section{Origem do MCMV Faixa 1}

O nome do programa que se está analisando é o Minha Casa, Minha Vida Faixa 1 para municípios urbanos com mais de 50 mil habitantes. A gestão que idealizou a política foi o governo do Presidente Luiz Inácio Lula da Silva, que já vinha ampliando o rol de medidas intervencionistas na economia a partir de seu segundo mandato, e, no caso do MCMV, tinha como objetivo adotar uma medida anticíclica de resposta à crise financeira de 2008/2009, para manter os níveis de renda e emprego no país ${ }^{10}$ por meio da produção de novas unidades habitacionais.

$\mathrm{O}$ "pacote habitacional" - nome que a imprensa havia conferido ao conjunto de medidas de estímulo ainda em gestação pelo governo no primeiro trimestre de 2009 - teve sua primeira formulação feita entre representantes do setor da construção civil e a equipe econômica do segundo governo Luiz Inácio Lula da Silva (ROLNIK, 2015, p. 300-303), com enfoque em disponibilização de crédito habitacional para a classe média, referenciada em políticas previamente testadas no México e no Chile.

Até a edição da Medida Provisória (MP) que daria juridicamente origem ao programa, o MCMV passaria por substanciais alterações decorrentes de pressões de setores do próprio governo ${ }^{11}$ para incluir entre as medidas de estímulo os subsídios quase integrais à moradia para a população com renda familiar entre zero e três salários mínimos (conhecida como Faixa 1) e, posteriormente, receberia algumas mudanças de parlamentares no Congresso Nacional na tramitação da Lei de Conversão da MP.

10 "De fato, diante do cenário de crise financeira mundial com o recrudescimento de seus impactos negativos sobre a atividade econômica, renda e nível de emprego do País é premente a necessidade de adoção de medidas de natureza anticíclicas no curto prazo, principalmente aquelas que possam garantir a melhoria da qualidade de vida da população de baixa renda e a manutenção do nível de atividade econômica." Trecho da Exposição de Motivos da Medida Provisória n⿳⺈ 459, de 25 de março de 2009, que deu origem à primeira fase do programa Minha Casa, Minha Vida (MCMV). A MPV no 459, de 2009, posteriormente convertida na Lei ํㅜ 11.977, de 7 de julho de 2009, e seu decreto regulamentador (Decreto $\mathrm{n}^{\mathrm{o}}$ 7.499, de 16 de junho de 2011) são as principais bases normativas do MCMV Faixa 1. É preciso frisar que as supracitadas normas foram alteradas diversas vezes ao longo de mais de uma década da política pública.

${ }^{11}$ Liderados especialmente pela Secretária Nacional de Habitação do Ministério das Cidades, Inês Magalhães (BONDUKI, 2009, p. 12). 
Desde então, entre 2009 e 2018, foram contratadas mais de 5 milhões de unidades habitacionais no total e mais de 1,5 milhões para a Faixa 1 segundo dados do governo (LIS, 2019), tornando o MCMV a política pública de provimento habitacional que mais produziu moradias populares no Brasil. ${ }^{12}$

Do ponto de vista econômico, as cifras declaradas também são relevantes: o volume de investimento já superou $\mathrm{R} \$ 300$ bilhões de reais ${ }^{13}$ (aproximadamente $5 \%$ do PIB) se considerada a utilização de recursos do Orçamento Geral da União (OGU) e do Fundo de Garantia por Tempo de Serviço (FGTS), além de ter gerado mais de 1 milhão de empregos diretos e indiretos pelo reaquecimento do setor (AGÊNCIA CAIXA DE NOTÍCIAS, 2014). A Faixa 1, por sua vez, que mobiliza essencialmente subsídios do OGU representa mais de $1 / 3$ desse total (INSTITUTO ESCOLHAS, 2018, p. 70).

\section{Desenho Federal do MCMV Faixa 1}

O MCMV identifica mais uma marca ${ }^{14}$ do que uma política pública uniforme, na medida em que as modalidades têm objetivos, públicos-alvo, fontes de financiamento e atores distintos em sua fase de implementação. Conforme já se indicou, esse artigo objetiva aprofundar apenas as modalidades da Faixa $1^{15}$ do programa destinadas a municípios com mais de 50 mil habitantes, cujo públicoalvo é a população com renda familiar de zero a três salários mínimos.

O MCMV Faixa 1 para cidades com mais de 50 mil habitantes funciona basicamente por meio de duas modalidades ${ }^{16}$. Conhecidas popularmente como "Entidades"17 e "Empresas", o fator essencial de diferenciação entre elas está em

${ }^{12}$ A título comparativo, o período de maior produção de habitação popular antecedente ao MCMV havia ocorrido durante a existência do Banco Nacional de Habitação (1964-1986), em que foram construídas pouco mais de 2.3 milhões de unidades para o público-alvo de baixa e média renda (BONDUKI, 2012, p. 64).

${ }^{13}$ Até o lançamento da $3^{\mathrm{a}}$ fase do MCMV em 2016, o governo havia indicado que o investimento atingira $\mathrm{R} \$ 294$ bilhões de reais. (MAIA, 2016).

${ }^{14}$ Expressão usada por Caio Santo Amore (2015, p.15) em livro que avaliou a implementação do Minha Casa, Minha Vida em seis estados do país.

${ }^{15}$ Devido ao reduzido espaço de um artigo, se dará preferência para a apresentação do atual arranjo jurídico-institucional do MCMV Faixa 1, ressalvando que este foi substancialmente alterado ao longo de mais de uma década da política pública, sendo que as alterações mais relevantes foram marcadas por meio de fases. Já foram lançadas três fases do $\operatorname{MCMV}(2009,2011$ e 2016).

${ }^{16}$ Apesar da existência de duas modalidades, a maioria absoluta dos empreendimentos do país destinados à Faixa 1 são construídos pelas empresas através do Fundo de Arrendamento Residencial. Ainda assim, São Paulo se destaca como sendo uma cidade excepcional, tendo em vista que as contratações da modalidade "Entidades" chegaram a 41,22\% do total da Faixa 1 até o fim de 2016 (ainda que muitas dessas unidades não tenham sido construídas em decorrência da falta de orçamento), enquanto no resto do país esse número atingiu apenas 5,85\% dos contratos (CHILVARQUER, 2018, p. 135).

${ }_{17}$ Ainda que tenham surgido em datas próximas, o Entidades é posterior ao Empresas, que era o cerne do programa pensado pelo governo. A criação do Entidades teve grande relação com a 
quem é responsável pela proposição de novos empreendimentos - se associações sem fins lucrativos ou empreiteiras.

Em ambos os casos, a União subsidia praticamente o valor integral da moradia ao beneficiário com recursos do Orçamento Geral da União, também utilizando os bancos públicos para sua operacionalização.

A lei que regulamenta o MCMV atualmente é a Lei Federal no 11.977, de 2009, que já foi objeto de diversas alterações legislativas. A norma que regulamenta o programa em âmbito federal é o Decreto no 7.499, de 16 de junho de 2011, exarado no dia do lançamento da segunda fase do programa ${ }^{18} \mathrm{e}$ assinado pelos ministros da Fazenda, Planejamento, Cidades e pela Advocacia-Geral da União, tendo recebido alterações em seus artigos $2^{\circ}$, $8^{\circ}$ e $10^{\circ}$ com o Decreto $n^{\circ}$ 7.795, de 2012, e em seus artigos $7^{\circ}$ e $8^{\circ}$ com o Decreto ํㅜ 7.825 de 2012.

Nos textos legais apontados, estão os requisitos ${ }^{19}$ para indicação dos beneficiários estipulados pelo governo federal, tais como o limite de renda familiar e as prioridades de atendimento (i.e. famílias residentes em áreas de risco, insalubres).

Além das indicações feitas na lei e no decreto, há relevante papel regulamentar legado ao Ministério das Cidades (fundido no Ministério do Desenvolvimento Regional pela Lei no 13.844, de 18 de junho de 2019, sendo suas competências assumidas pela Secretária Especial das Cidades), como os limites de subsídio máximo por unidade habitacional em diferentes localidades do país e os parâmetros de priorização de beneficiários, inclusive aqueles que envolvem atuação dos entes locais, que são regulados por meio de normas infradecreto.

Ainda, cabe ao órgão federal estipular o número máximo de unidades habitacionais por empreendimento, tratar do padrão dos imóveis e da infraestrutura urbana necessária para sua construção, bem como detalhar como será o termo de adesão do MCMV entre a União e Estados e Municípios, abordando, sobretudo, quais são as contrapartidas dos entes locais para receber recursos do programa. Em geral, tais contrapartidas estão relacionadas à doação de terrenos para empreendimentos, à complementação de recursos para viabilizar as

organização e cobrança dos movimentos sociais de moradia organizados em torno do Fórum Nacional de Reforma Urbana entre o final de 2008 e começo de 2009 sobre o Ministério das Cidades e a então Ministra-Chefe da Casa Civil, Dilma Rousseff (RODRIGUES, 2013, p. 72-76)

${ }^{18}$ Em cada lançamento, além de alterações legislativas, que buscavam adequar o programa a novas diretrizes governamentais, as próprias metas do programa eram reorientadas. Ou seja, utilizando a "marca" MCMV, o governo federal priorizou mais as Faixas 2 e 3 na $1^{\text {a }}$ fase do programa $(60 \%$ dos recursos foram alocados nas Faixas 2 e 3 entre 2009 e 2011), e, posteriormente, a partir da $2^{a}$ fase do programa, reorientou suas prioridades passando a alocar mais recursos para a Faixa 1 (60\% dos recursos foram alocados na Faixa 1 a partir de 2011) (AMORE, 2015, p. 19-22). A partir de 2016, as diferentes gestões do Ministério das Cidades apresentaram metas de contratações que foram seguidamente descumpridas por contingenciamentos orçamentários.

${ }^{19}$ Art. 3o da Lei 11.977, de 2009. 
construções e à disponibilização de áreas com infraestrutura urbana, como luz elétrica, água e esgotamento sanitário.

Já aos Ministérios do Planejamento e Fazenda (atualmente fundidos no Ministério da Economia pela Lei $\mathrm{n}^{\mathrm{o}}$ 13.844, de 2019), em conjunto com o antigo Ministério das Cidades, cabe o detalhamento dos limites de subvenção para beneficiários Faixa 1, formas de pagamento, valor mínimo das prestações pagas pelos beneficiários e a remuneração da Caixa Econômica Federal pelas operações.

Diante desse quadro, vê-se que a Secretaria das Cidades fica prioritariamente com temas referentes ao mérito do programa, ou seja, a delimitação do públicoalvo, as regras gerais de inserção urbanística dos empreendimentos e a relação com outros entes federativos, bancos públicos e entidades organizadoras na execução do programa. Já a área econômica do governo federal influi essencialmente na operacionalização financeira da política pública (i.e. disponibilização orçamentária), que é absolutamente central para o MCMV Faixa 1, na medida em que o programa depende fundamentalmente de recursos orçamentários para viabilizar os subsídios habitacionais.

Os bancos públicos federais, especialmente a Caixa Econômica Federal, são os principais agentes na operacionalização da política. Além de haver um relevante papel desses entes como agentes financiadores, ou seja, o braço operacional que garante o crédito do programa ${ }^{20}$.

Quanto ao papel de Estados e Municípios, o MCMV Faixa 1 não é automaticamente implementado pelo governo federal, mas depende de atuação ativa dos entes locais para sua execução. Entre as suas responsabilidades, ${ }^{21}$ tanto na modalidade Entidades como Empresas, estão (i) a desoneração tributária para as empresas que atuem na construção de habitação de interesse social; (ii) doação de terrenos localizados em área urbana consolidada para implementação dos empreendimentos vinculados ao programa; (iii) a implementação dos instrumentos do Estatuto da Cidade, voltado à retenção de áreas de ociosidade, como implantação de zonas especiais de interesse social (ZEIS); (iv) instalação ou ampliação de equipamentos e serviços públicos relacionados a educação, saúde, lazer e transporte público (v) a fixação de critérios locais de seleção de beneficiários do MCMV, previamente aprovados pelos respectivos conselhos locais de habitação; e (iv) o licenciamento dos empreendimentos propostos no âmbito municipal.

As principais diferenças entre a regulação do MCMV-Empresas e o MCMVEntidades estão no cadastramento e indicação de beneficiários, na execução do

\footnotetext{
${ }^{20}$ A partir de 2011, quando do início da segunda fase do Programa, a Caixa Econômica Federal perdeu a exclusividade como agente financiadora do MCMV, sendo que o Banco do Brasil passou a atuar na área. Segundo reportagem veiculada na época, a ideia era ampliar o número de agentes financiadores do programa para viabilizar os dois milhões de moradias previstos na segunda fase do Programa. (LIMA, 2011.)

${ }^{21}$ Art. $3^{\circ}$, $\S \S 1^{\circ}$, $3^{\circ}$ e $5^{\circ}$ da Lei 11.977, de 2009 e art. 23 do Decreto 7.499, de 2011.
} 
Trabalho Técnico Social ${ }^{22}$ e na seleção dos terrenos a serem construídos os empreendimentos. Enquanto no MCMV-Empresas essas tarefas ficam com os entes locais (Estados e Municípios), no MCMV-Entidades essas atividades estão vinculadas às Entidades Organizadoras.

Para facilitar a compreensão, indica-se os fluxogramas do MCMV-Empresas e Entidades nas figuras 1 e 2 .

Figura 1: Fluxograma do MCMV Faixa 1 “Empresas” - FAR

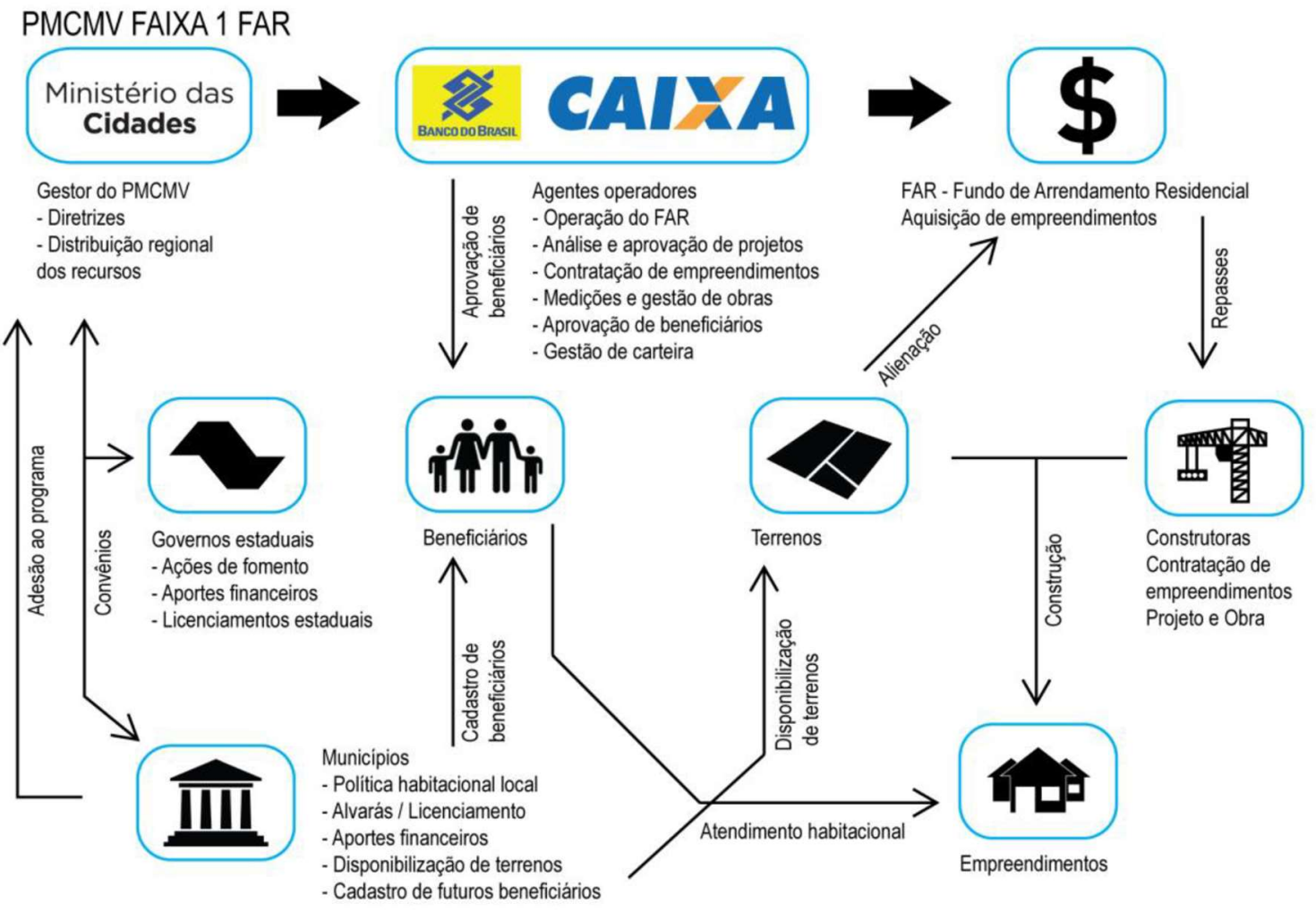

Fonte: Acosta (2015).

${ }^{22}$ De acordo com o Manual de Orientação da Caixa Econômica Federal, é "o conjunto de ações que visam promover a autonomia e o protagonismo social, planejadas para criar mecanismos capazes de viabilizar a participação dos beneficiários nos processos de decisão, implantação e manutenção dos bens/serviços, adequando-os às necessidades e à realidade dos grupos sociais atendidos, além de incentivar a gestão participativa para a sustentabilidade do empreendimento". Disponível em http://portal.cnm.org.br/sites/6700/6745/caderno_de_orientacao.pdf. Último acesso em 11 de maio de 2019. 
Figura 2: Fluxograma do MCMV Faixa 1 "Entidades" - FDS

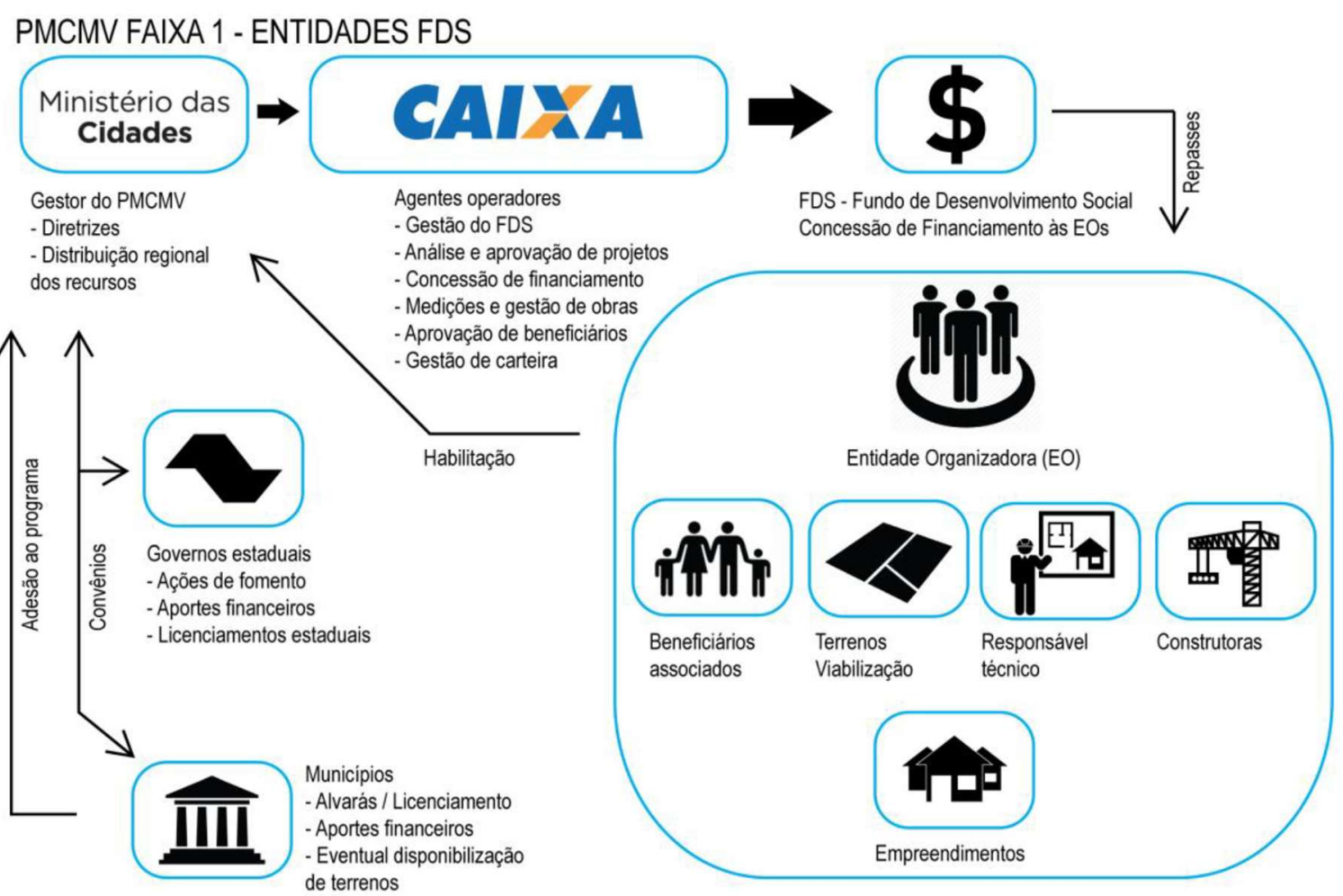

Fonte: Acosta (2015).

\section{IMPLEMENTAÇÃO DO MCMV FAIXA 1 NO MUNICÍPIO DE SÃO PAUlo}

Conforme se demonstrou, o esforço para entender o MCMV Faixa 1 deve ir do arranjo geral - predominantemente estruturado no âmbito federal - ao impacto territorial23 ${ }^{23}$, cujo protagonismo é essencialmente municipal, pois são esses entes que

${ }^{23}$ Apesar de não aprofundar o tema no presente artigo, o MCMV Faixa 1 é indubitavelmente um caso importante de coordenação interfederativa a ser estudado por acadêmicos do direito. 
detêm um conjunto de instrumentos urbanísticos instituídos na Constituição Federal de 1988 e ampliados ou regulados em leis posteriores.

Além disso, em consonância com o que se pode depreender das competências gerais do programa elencados no item anterior, os entes locais têm importância central na implementação do MCMV Faixa 1. Nesse sentido, a literatura especializada (BONDUKI, 2009, p. 13; FERREIRA, 2012, p. 7-9; ROLNIK et al., 2010, passim; ROLNIK; SANTORO, 2013, p. 13-18; ROLNIK et al., 2014, passim) já indicou que a atuação dos Municípios é central na escolha tanto do MCMV como ferramenta de provimento de habitação de interesse social em âmbito local, quanto no tipo de produção (volume, qualidade dos empreendimentos, inserção urbanística etc.) que é gerada a partir desse financiamento federal.

Nesse sentido, é importante ressaltar que os achados da implementação do MCMV Faixa 1 no Município de São Paulo não podem ser extrapolados para o resto do país. Apesar disso, é possível que as soluções jurídicas encontradas para superar os entraves da política pública na maior cidade do país possam ser total ou parcialmente aproveitadas por outros municípios - um dos objetivos centrais da adoção de um método como o Quadro de Referência.

No caso paulistano, a escolha dos gestores públicos municipais por viabilizar parte do provimento de Habitação de Interesse Social (HIS) da cidade via MCMV Faixa 1 foi célere e atestada tanto pela análise documental ${ }^{24}$ como pela entrevista $^{25}$ conduzida com o então Secretário adjunto de Habitação do Município e presidente da COHAB-SP, ${ }^{26}$ Ricardo Pereira Leite, que enxergou, a partir do lançamento do programa federal em 2009, mais uma fonte de recursos para viabilizar a política setorial da cidade.

A partir de então, o MCMV Faixa 1 foi ganhando cada vez mais protagonismo no provimento de Habitação de Interesse Social (HIS) de São Paulo, tornando-se, ao longo dos anos, a principal fonte de produção habitacional para a população de

\footnotetext{
${ }^{24} \mathrm{O}$ primeiro Termo de Adesão entre a Prefeitura de São Paulo e a Caixa Econômica Federal para o início da implementação do programa foi assinado no dia 30 de abril de 2009, pouco mais de um mês da edição da Medida Provisória 459, de 25 de março de 2009, que deu origem ao MCMV.

${ }^{25}$ As entrevistas apresentadas a partir desse trecho são fruto do trabalho de mestrado do autor (CHILVARQUER, 2018). Em entrevista concedida no dia 23 de novembro de 2017, ao ser questionado sobre a relevância do programa para a política de provimento de HIS, o secretário narrou: "Era relevante (...) o CDHU tem dinheiro, porque eles têm recurso, um percentual do orçamento... então o Estado, de pronto, não aderiu ao Minha Casa Minha Vida, ficou um pouco resistente. Eu falei: 'Eu sou pobre, não sou orgulhoso, vamos aderir!'." Ao explicar o que motivou a adesão, Ricardo Pereira Leite aponta que o município precisava de todos os recursos que pudesse conseguir para implementar sua política habitacional: "Então, o Minha Casa Minha Vida, na minha visão: 'Opa! Arrumei um pedacinho do que eu preciso pra fazer habitação!'."

${ }^{26}$ No âmbito local (Estado e Município de São Paulo), a Secretaria de Habitação (SEHAB) e a Companhia Metropolitana de Habitação $(\mathrm{COHAB})$ são os principais órgãos responsáveis pela implementação da política habitacional no município de São Paulo.
} 
baixa renda na cidade. Dados da Caixa Econômica Federal ${ }^{27}$ indicam a contratação, na cidade, de 65 empreendimentos entre dezembro de 2009 e dezembro de 2016, que totalizam 19.749 novas unidades habitacionais e resultam em um valor total investido de pouco mais de $\mathrm{R} \$ 950$ milhões de reais.

Frise-se, entretanto, que os números de contratação do MCMV Faixa 1 não demonstram de maneira precisa os esforços empreendidos para viabilizar a política na cidade. Isso se dá por três motivos principais. $O$ primeiro ocorre porque unidades contratadas não correspondem necessariamente a imóveis entregues aos beneficiários, na medida em que ainda é preciso considerar o período de obras dos empreendimentos. Isto é, existe um "tempo do programa", 28 que vai da proposta inicial até o recebimento das chaves, e isso implica que se passam anos até que se gere o impacto final da política - novas moradias entregues para a população mais pobre da cidade.

Já o segundo se dá porque há todo um trabalho realizado pela Prefeitura que antecede o período de contratação pela Caixa Econômica Federal, como o licenciamento dos empreendimentos, a desapropriação de terrenos para doação pelo Município, como contrapartida ${ }^{29}$ pelo recurso federal do $\mathrm{MCMV}$, e o chamamento público para que empresas e entidades organizadoras executem as obras nessas glebas doadas pela Prefeitura.

Há, por fim, um motivo alheio à governança da Prefeitura para essa lacuna entre obras contratadas e o esforço dispendido para viabilizar o programa na cidade: para que a Caixa contrate novas unidades habitacionais pelo MCMV Faixa 1, é preciso haver recursos orçamentários, disponibilizados pelo governo federal, que lastreiem os empreendimentos, mesmo que os processos estejam completamente prontos no âmbito municipal.

Em outras palavras, em tempos restrição fiscal do governo central como o que ocorre desde o início de 2015, pouco importa o esforço do Município para viabilizar o MCMV Faixa 1 localmente, já que sua principal matéria-prima - os subsídios federais - não chega para garantir o início da produção. ${ }^{30}$

\footnotetext{
${ }^{27}$ Disponíveis em http://www.caixa.gov.br/Downloads/minha-casa-minha-vida-empreendimentospessoa-fisica/Empreendimentos_MCMV_PJ.zip. Último acesso em 11 de maio de 2019.

28 Por "tempo do programa" entende-se o prazo necessário para viabilizar um empreendimento do MCMV Faixa 1 no município, envolvendo a disponibilização de um terreno, público ou privado, para construção, o licenciamento do empreendimento, a contratação do projeto na CEF, o prazo de execução das obras, a seleção de beneficiários dos imóveis, a realização do trabalho técnico social de pré-ocupação com os futuros moradores e a liberação final do imóvel para entrega dos apartamentos aos usuários finais.

${ }^{29}$ Art. $3^{\circ}$, §1으, I da Lei 11.977, de 2009.

${ }^{30}$ Para ilustrar esse argumento, de acordo com dados da Caixa Econômica Federal, em 2012 e 2013, anos com maior nível de contratação do MCMV Faixa 1, foram assinados 389.073 e 557.961 contratos, respectivamente. Já em 2015 e 2016 foram assinados 16.890 e 31.900 acordos, respectivamente. Nos últimos anos, os constantes cancelamentos em decorrência de cortes orçamentários tornaram os dados sobre contratação pouco úteis para comparação. A entrevistada Marcia Terlizzi deu um retrato da situação: “Foram investidos na ordem de R $\$ 750$ milhões só para
} 
APLICANDO O QUADRO DE REFERÊNCIA PARA ANÁLISE JURÍDICA DE POLÍTICAS PÚblicAS: A IMPLEMENTAÇÃO DO PROGRAMA MinHA CASA, MinHA VIDA, FAIXA 1, NO MUNICÍPIO DE SÃO PAULO

Para que se tenha uma ideia desse lapso, desde 2013 mais de 28 mil unidades foram previstas e praticamente em sua totalidade ainda não se transformaram em contratações efetivadas pela Caixa. Do ponto de vista jurídico, essa intenção foi formalizada em 12 editais de chamamentos públicos da COHAB para que empresas e entidades produzissem em glebas disponibilizadas pelo Município, em sua maioria decorrentes de processos de desapropriação específicos para esse fim.

Para movimentar toda essa máquina que é a implementação do MCMV Faixa 1 em uma cidade como São Paulo, as dificuldades do município são enormes, e podem ser encontradas em praticamente todas as atribuições que a legislação federal delegou às Prefeituras: na doação de terras públicas, nas desapropriações, na implementação dos instrumentos do Estatuto da Cidade com objetivo de controle da retenção das áreas urbanas em ociosidade, no cadastramento e na indicação dos beneficiários, no licenciamento dos imóveis, no acompanhamento das associações sem fins lucrativos no âmbito do "Entidades", no trabalho técnico social de ocupação dos imóveis e até nos grupos de acompanhamento dos empreendimentos para realização dos Relatórios de Diagnóstico de Demanda (RDD) por Equipamentos e Serviços Públicos e Urbanos elaborado pelo Grupo de Análise de Empreendimentos (GAE).

Não obstante, esses obstáculos na implementação geraram interessantes adaptações que nada mais são do que a utilização do direito para alterar os rumos da política pública. Nesse sentido, novas estruturas burocráticas, novos procedimentos administrativos, uso de instrumentos de tecnologia da informação e inovações forçadas pelo Município nas regras do programa federal são apenas alguns capítulos da história que foi a implementação do MCMV Faixa 1 pelo Município, conforme se verá no próximo item.

\section{ENTRAVES E INOVAÇÕES JURÍDICAS NA IMPLEMENTAÇÃO DO MCMV FAIXA 1 NO MUNICÍPIO DE SÃo PAULO}

São Paulo possui o maior déficit habitacional e inadequação domiciliar absoluto do país, ${ }^{31}$ além da grande dificuldade de acesso à terra para novas construções em decorrência do alto preço do metro quadrado de construção ${ }^{32}$ no município.

aquisição de terrenos para o MCMV. E foram licenciados, praticamente, 34 ou 43 mil unidades... Ou seja, tinha terreno e quando isso casou, não tinha mais dinheiro [risos] e acabou... Foi o final de 2016, ficou o ano de 2016 inteiro... E continua agora".

${ }^{31}$ O Plano Municipal de Habitação de 2016, baseando-se em dados da Fundação João Pinheiro, estimou em 358.097 domicílios o déficit habitacional e 272.097 domicílios em situação de inadequação (SEHAB, 2016, p.21).

${ }^{32}$ Segundo pesquisa FIPEZap finalizada em 2017, São Paulo é a segunda cidade mais cara do país, com custo médio de $\mathrm{R} \$ 8.680$ reais para cada $\mathrm{m}^{2}$. (EXAME, 2017) 
Se as demandas habitacionais são relevantes, São Paulo também é um interessante caso de cidade com um longo histórico de uso inovador de instrumentos urbanísticos em seu passado. Muito antes de a Constituição de 1988 exigir que os municípios organizassem seu desenvolvimento urbano por meio de Planos Diretores, São Paulo já possuía legislação específica de planificação de seu território (o Plano Diretor de Desenvolvimento Integrado de 1971) e desenvolveu ferramentas de exploração da mais-valia urbana como a outorga onerosa do direito de construir ${ }^{33}$ e os certificados de potencial adicional de construção (CEPAC) ${ }^{34}$,cujos recursos vêm sendo parcialmente subvinculados para construção de HIS na última década.

Do ponto de vista burocrático, ainda que sejam recorrentes as críticas à sua atuação, a mera existência de uma empresa pública municipal com mais de cinquenta anos de experiência no provimento de HIS, como a Companhia Metropolitana de Habitação (COHAB) de São Paulo, e a existência de uma empresa pública de planejamento urbano, como a SP-Urbanismo, chama atenção. Ainda, no período recente, o Plano Diretor da cidade inovou mais uma vez ao instituir mecanismos para ligar a captura de valor de empreendimentos das áreas mais ricas ao provimento de habitação de interesse social, como a cota de solidariedade. ${ }^{35}$

Por todos esses motivos, o município de São Paulo possui uma complexidade bastante particular em relação à implementação do MCMV Faixa 1 no país: se de um lado há um histórico jurídico-institucional que possibilitaria a execução facilitada da política (instrumentos urbanísticos, memória institucional de empresa pública especializada), de outro, as condições econômicas, sociais e fundiárias da cidade constituem entraves a efetivação desta forma de provimento de HIS.

Para solucionar o entrave econômico do preço da terra na implementação do MCMV Faixa 1, o município lançou mão de um conjunto de medidas legislativas e administrativas claras adotadas em São Paulo que buscaram solucionar a dificuldade da insuficiência de recursos para produzir MCMV na cidade.

Ainda que o próprio governo federal já houvesse, por meio de regulamentação nacional, previsto subsídios maiores para a cidade ${ }^{36}$, o custo da terra na cidade

\footnotetext{
${ }^{33}$ No atual Plano Diretor Estratégico do Município de São Paulo (art. 340, I da Lei Municipal no 16.050, de 31 de julho de 2014), ficou legalmente estabelecida a subvinculação de $30 \%$ dos recursos do Fundo de Desenvolvimento Urbano para "aquisição de terrenos destinados à produção de Habitação de Interesse Social localizados na Macroárea de Estruturação Metropolitana, e na Macroárea de Urbanização Consolidada e na Macroárea de Qualificação da Urbanização, preferencialmente classificados como ZEIS 3".

${ }^{34}$ Atualmente existem quatro Operações Urbanas no Município de São Paulo, sendo que três delas - Operações Urbanas Consorciadas Água Branca (22\%), Água Espraiada (10\%) e Faria Lima (10\%) - preveem subvinculação dos recursos captados para viabilização de habitações de interesse social.

${ }^{35}$ Arts. 111 e 112 do Plano Diretor Estratégico (Lei Municipal no 16.050, de 31 de julho de 2014).

${ }^{36}$ Além de São Paulo, Rio de Janeiro e o DF também possuíam nível de subsídio por unidade habitacional superior.
} 
APLICANDO O QUADRO DE REFERÊNCIA PARA ANÁLISE JURÍDICA DE POLÍTICAS PÚblicAS: A IMPLEMENTAÇÃO DO PROGRAMA MinHA CASA, MinHA VIDA, FAIXA 1, NO MUNICÍPIO DE SÃO PAULO

obrigou o governo estadual e municipal a utilizar uma complementação do aporte aos beneficiários do programa.

$\mathrm{O}$ "20-20", como ficou conhecido, previa uma subvenção complementar de R\$ 20 mil reais de cada ente (Estado e Município) ao subsídio federal do MCMV Faixa 1 para "fechar a conta" dos empreendimentos. Nesse sentido, o subsídio máximo da unidade habitacional, que atualmente, pelas regras federais, é de R\$96 mil, passou a ser, na prática, de $\mathrm{R} \$ 136 \mathrm{mil}$ ou, pelo menos, de $\mathrm{R} \$ 116$ mil quando apenas um dos entes locais aceitava fazer o aporte de $\mathrm{R} \$ 20 \mathrm{mil}^{37}$.

Do ponto de vista normativo, os aportes só foram viabilizados mediante expressa autorização legal, e posteriormente regulamentados via decreto. Em âmbito estadual, o programa foi denominado de Casa Paulista ${ }^{38}$ e foi regulamentado pelos Decretos Estaduais no 55.963, de 29 de junho de 2010, (Entidades) e no 56.423, de 22 de novembro de 2010 (Faixa 1 em geral).

Já o programa municipal foi chamado de Casa Paulistana e é mais recente, criado pela Lei Municipal no 16.006, de 4 de junho de 2014, e regulamentado pelo Decreto Municipal no 55.584, de 10 de outubro de 2014, que pressupõe a assinatura de termos de cooperação com a SEHAB. Antes de se tornar programa de governo, segundo o ex-secretário Ricardo Pereira Leite, a complementação era viabilizada "caso a caso" com recursos do Fundo Municipal de Habitação (FMH), que é controlado por uma instância de participação social com representantes do governo e da sociedade civil - o Conselho Municipal de Habitação.

Sobre os números do Casa Paulistana, segundo dados da SEHAB (2016, p. 76), desde sua criação em 2014 o programa alocou $\mathrm{R} \$ 58,4$ milhões de reais e colaborou com a viabilização de 6.393 unidades habitacionais.

Apesar da inovação no aporte "20-20", ainda assim houve dificuldades para que o setor privado e as entidades viabilizassem empreendimentos com os subsídios estatais em terrenos próprios. Não era apenas o aspecto econômico que pesava para isso, mas também uma questão relacionada à qualidade e à inserção urbanística dos empreendimentos apresentados pelo setor privado. Conforme tratado de maneira extensa na literatura (AMORE et al., 2015; CARDOSO et al., 2013; KRAUSE; BALBIM; NETO, 2013; KLINTOWITZ, 2016), o fato de as construtoras serem as responsáveis pelo provimento, e sendo o subsídio limitado e o preço de construção pouco variável, os empresários tendem a buscar ganhos econômicos na redução do preço da terra e na ampliação da escala dos empreendimentos.

\footnotetext{
${ }^{37}$ Não há necessariamente correlação entre o complemento estadual e o municipal. Nesse sentido, é perfeitamente possível que o município aceite fazer a complementação e o Estado não ou viceversa.

${ }^{38}$ O projeto Casa Paulista abrange mais programas além do MCMV Faixa 1, como iniciativas de parceria-público privadas habitacionais.
} 
Diante desse desafio fundiário, a solução adotada pela Prefeitura, especialmente a partir de 2013, foi tentar desatar o "nó da terra" através de outra contrapartida municipal prevista na legislação federal: ${ }^{39}$ a doação de terrenos públicos.

Para viabilizar essas doações, a Prefeitura poderia atuar de duas maneiras: desmobilizando ativos próprios do município ou desapropriando terrenos de particulares para doar ${ }^{40}$ a quem se disponibilizasse a construir os empreendimentos.

Juridicamente, as doações de terrenos significavam repassar os terrenos da Prefeitura para os fundos financeiros que viabilizavam as modalidades do MCMV - o FAR e FDS -, e realizar (ou a Prefeitura ou a CEF) chamamentos para seleção de empresas ou entidades para viabilizar as obras. Do ponto de vista normativo, tal prática era facilitada, na medida em que a Lei Orgânica do Município dispensa autorização legislativa e licitação para imóveis construídos ou destinados a programas habitacionais de interesse social (art. 112, $\$ 1^{\circ}$, I, ' $a$ ').

Já as desapropriações ${ }^{41}$ envolvem um rito que abrange diversos passos e secretarias, como a edição do decreto de interesse social, ${ }^{42}$ a elaboração de plantas expropriatórias, realização de avaliação ou indicação de valor venal e, quando não houvesse acordo com o expropriado - o que ocorria na imensa maioria dos casos , a proposição de ação de desapropriação.

A partir da gestão Fernando Haddad (2013-2016), esse processo de formação de um banco de terras foi substancialmente acelerado. ${ }^{43}$ Só em desapropriações de terrenos, a Prefeitura gastou $\mathrm{R} \$ 617$ milhões de reais (SEHAB, 2016, p. 52-53), o que, de acordo com a Secretaria de Habitação, seria suficiente para viabilizar 31 mil novas unidades habitacionais, fosse com recursos do MCMV Faixa 1 ou com valores das Operações Urbanas.

A título de comparação, os valores investidos equivalem a praticamente $2 / 3$ do total de subsídios federais nos empreendimentos do MCMV Faixa 1 contratados até hoje na cidade, e doze mil unidades a mais em relação ao total de unidades habitacionais contratadas até agora.

Ao longo do tempo de implementação ocorreu uma alteração procedimental em relação à forma de disponibilizar os terrenos adquiridos para produção, porém não se conseguiu precisar quando a mudança ocorreu. Enquanto no início da

\footnotetext{
${ }^{39}$ Art. 3ํ, §1ํㅡ, I da Lei 11.977, de 2009.

${ }^{40}$ Tecnicamente a doação não é ao privado, mas aos fundos financeiros (FAR e FDS) que garantem a implementação da política pela Caixa Econômica.

${ }^{41}$ No âmbito municipal regulado pelo Decreto 53.799, de 2013.

${ }^{42}$ Regulamentado pela Lei no ${ }^{\circ} .132$, de 10 de setembro de 1962.

${ }^{43}$ Sobre o tema, Marcia Terlizzi, assessora especial da SEHAB até o fim de 2018 e única entrevistada que participou de todas as gestões desde o lançamento do programa, afirmou: "Tem a ver com mudança de postura. Em 2013 a meta basicamente do prefeito Haddad era de 55 mil unidades... e o programa naquela época estava forte e tinha o alinhamento político... foi a época que mais se investiu no MCMV e nos dois aspectos importantes para ele se manter em pé: terras e o licenciamento."
} 
APLICANDO O QUADRO DE REFERÊNCIA PARA ANÁLISE JURÍDICA DE POLÍTICAS PÚBliCAS: A IMPLEMENTAÇÃo do PROGRAMA Minha CASA, MinHa VidA, FAiXA 1, NO MUNICÍPIO DE SÃO PAULO

implementação da política os terrenos próprios e desapropriados eram repassados para a Caixa Econômica Federal, ${ }^{44}$ que realizava então chamamentos públicos para empresas e entidades, a partir de 2014 (Chamamento 001/2014 para MCMV-FAR), a COHAB passou a se responsabilizar pela convocação.

Embora pareça uma questão menor, o fato de o chamamento ser de responsabilidade do órgão municipal, em tese, amplia a sua governança sobre o que será feito com o terreno. Frise-se que não se está falando da alteração do instrumento jurídico que viabiliza essa parte da implementação da política, mas sim do responsável pelo controle do seu conteúdo, o que pode gerar um efeito relevante na política. Em outras palavras, o controle desses editais também representa a escolha de qual modalidade do MCMV Faixa 1 os gestores municipais priorizam - se o "Empresas" ou "Entidades".

É importante destacar que para a formação do banco de terras, importantes adaptações burocráticas foram necessárias, especialmente na SEHAB e COHAB, que eram executoras do programa no Município.

Outra importante mudança na burocracia está vinculada ao licenciamento dos empreendimentos. Essa tarefa é um dos fatores mais relevantes daquilo que chamamos de "tempo do programa" do MCMV Faixa 1, isto é, o prazo entre o início da prospecção da empreiteira ou entidade para construção de um imóvel e a entrega final das chaves aos beneficiários.

Para superar esse desafio, a Prefeitura adotou medidas de gestão como a instituição de uma Subcomissão de Análise Integrada de Empreendimentos Habitacionais de Interesse Social - SAEHIS, no âmbito da então recém-criada Secretaria Municipal de Licenciamento (SEL).

A subcomissão, criada pelo Decreto Municipal 54.297 de 2 de setembro de 2013, instituía uma série de medidas simplificadoras, como a unificação de diversos processos de licenciamento em um grupo intersecretarial especialmente focado no licenciamento de HIS, e a criação de uma Secretaria Executiva, vinculada à SEL, para acompanhar o andamento dos procedimentos.

Do ponto de vista jurídico, uma alteração administrativa viabilizada mediante edição de um decreto do Poder Executivo garantiu uma relevante simplificação de procedimentos, bem como um locus de comunicação entre as diversas secretarias que atuam no processo de licenciamento. Nesse sentido, uma atuação que era uma atribuição legal da Prefeitura passou a ser feita de maneira mais eficiente e coordenada, o que reforça o papel funcional do direito na viabilização das políticas públicas defendido por Coutinho (2013a).

${ }^{44}$ Entrevista do ex-Secretário Ricardo Pereira Leite: “Eu dava o terreno pra Caixa Econômica, que por sua vez, fazia uma licitação e a empresa ganhava a construção da habitação, e a demanda era da minha, eu que indicava." 
Quanto aos instrumentos de direito urbanístico, o município de São Paulo lançou mão de duas ferramentas bastantes tradicionais de indução de provisão de HIS e outro bastante inovador: as Zonas Especiais de Interesse Social (ZEIS) ${ }^{45}$, a vinculação de recursos do Fundo de Desenvolvimento Urbano e a cota de solidariedade ${ }^{46}$.

Conforme apontado por Santoro e Borelli, as ZEIS surgiram inicialmente nos anos 1980 para "reconhecer a existência de assentamentos informais e viabilizar sua consolidação" (SANTORO; BORELLI, 2015, p. 02-03). Inicialmente limitado às ZEIS de regularização, esse tipo de zoneamento foi estendido para demarcar áreas consideradas subutilizadas, que ficaram conhecidas como "ZEIS de vazios". No caso do Município de São Paulo, é preciso esclarecer que existem diferentes tipos de ZEIS para atingir objetivos distintos. No Plano Diretor de 2002, havia quatro tipos de ZEIS, sendo a ZEIS 1 "de regularização" e as ZEIS 2, 3 e 4 de "vazios". A partir do PDE de 2014 houve substancial aumento na demarcação de ZEIS, além da criação de mais uma ZEIS "de vazios", a ZEIS 5, para áreas em que houvesse interesse de criação de habitação de mercado popular (HMP) ou HIS.

Sua função, de acordo com apresentação ${ }^{47}$ da Secretaria Municipal de Licenciamento, é evitar que o mercado imobiliário "empurre" a população de menor renda para as periferias, gerando prejuízos tanto às famílias de baixa renda, que passam a viver distantes do centro, em áreas sem infraestrutura, quanto ao todo da cidade, acarretando deseconomias na infraestrutura e no sistema de transportes, além da ocupação de áreas de proteção ambiental pela população afastada do centro.

Sobre esse tema, diversos autores (RIBEIRO et al., 2016, p. 453; SANTORO et al., 2015, p. 08; ROLNIK; SANTORO, 2013, p. 15) indicam que houve uma ampliação da produção de HIS em ZEIS a partir do lançamento do MCMV, alterando uma tendência anterior de menor produção nessas áreas - o que, para muitos, tornava o instrumento urbanístico algo pouco efetivo em relação à sua missão primordial.

É difícil afirmar se há um motivo que ensejou essa transição, mas é possível especular que, com uma maior disponibilidade de recursos garantida pelo MCMV, o volume de empreendimentos cresceu e com isso se ampliou uma busca por

\footnotetext{
${ }^{45}$ De acordo com o art. 12 do Plano Diretor Estratégico (PDE) de São Paulo, as ZEIS são "porções do território destinadas, predominantemente, à moradia digna para a população de baixa renda por intermédio de melhorias urbanísticas, recuperação ambiental e regularização fundiária de assentamentos precários e irregulares, bem como à provisão de novas Habitações de Interesse Social - HIS e Habitações de Mercado Popular - HMP, a serem dotadas de equipamentos sociais, infraestrutura, áreas verdes e comércio e serviços locais, situadas na zona urbana."

${ }^{46}$ De acordo com o art. 111 do PDE: "que consiste na produção de Habitação de Interesse Social pelo próprio promotor, doação de terrenos para produção de HIS ou a doação de recursos ao Município para fins de produção de Habitação de Interesse Social e equipamentos públicos sociais complementares à moradia (art. 111)."

47 Disponível em http://www.prefeitura.sp.gov.br/cidade/secretarias/upload/licenciamentos/ zeisplanodiretor.pdf. Acesso em: 11 de maio de 2019.
} 
APLICANDO O QUADRO DE REFERÊNCIA PARA ANÁLISE JURÍDICA DE POLÍTICAS PÚBliCAS: A IMPLEMENTAÇÃo do PROGRAMA Minha CASA, MinHa VidA, FAiXA 1, NO MUNICÍPIO DE SÃO PAULO

terrenos na cidade, implicando o aumento dos preços das glebas, e tornando as ZEIS - que limitam as possibilidades de uso das construções - mais atrativas para implementar HIS.

Apesar de não haver dados consolidados sobre a produção de empreendimentos do MCMV Faixa 1 em ZEIS emitidos pela Prefeitura, os gestores municipais entrevistados para a realização desta dissertação foram categóricos sobre a sua importância para a facilitação do provimento de HIS na cidade, pois a limitação de uso do terreno tornava sua desapropriação mais barata.

Além da demarcação em si, a regulação municipal a partir de 2014 alterou a própria conceituação do que era uma HIS de forma a se aproximar dos valores do MCMV Faixa 1, evitando que esses terrenos fossem aproveitados para empreendimentos do MCMV Faixa 2, cujo público-alvo era menos vulnerável e mais interessante economicamente às construtoras.

Outro ponto relevante do PDE 2014 foi o aporte garantido à política de HIS pela vinculação do Fundo de Desenvolvimento Urbano (FUNDURB). O FUNDURB é um instrumento relevante de captação da mais-valia urbana, isto é, da valorização obtida pelo privado em decorrência do processo de urbanização promovido pelo público. Isto ocorre porque uma das principais fontes de recursos deste fundo vem da outorga onerosa do direito de construir (OODC), que basicamente é uma possibilidade dada ao privado de construir acima do potencial construtivo de determinado zoneamento, em troca de uma contrapartida financeira.

Apesar de já existir no PDE de 2002,48 a partir de do PDE de 2014, ${ }^{49}$ se vinculou $30 \%$ do total de recursos do FUNDURB. Nesse sentido, uma mudança legal entre os dois Planos Diretores, que não alterou a destinação, mas especificou o volume de recursos a ser destinado à política habitacional, foi o gatilho que impactou de maneira extremamente positiva o financiamento da política setorial, sendo o MCMV Faixa 1 a principal ação governamental associada ao conjunto de desapropriações possibilitado pela vinculação do FUNDURB.

Na prática, o referido fundo se tornou uma fonte importante de recursos para a política habitacional, garantindo mais de 112 milhões de reais só no orçamento de 2015, conforme Balanço de Gestão da SEHAB (2016, p. 68).

A principal inovação de direito urbanístico no PDE de 2014 foi a cota de solidariedade. Denominada por Santoro e Borelli (2015, p. 13-14) de uma política habitacional inclusiva, diversas críticas foram formuladas ao longo da tramitação legislativa do mais recente PDE, pois houve uma substancial mudança em relação ao conteúdo enviado pelo Executivo.

A proposta inicial da Prefeitura era a garantia de que empreendimentos com áreas computáveis acima de $20.000 \mathrm{~m}^{2}$ destinassem $10 \%$ do próprio terreno para a

${ }^{48}$ Arts. 235 a 238 da Lei 13.430, de 2002.

${ }^{49}$ Arts. 337 a 342 da Lei 16.050, de 2014. 
produção de HIS. Isso geraria uma possibilidade de mistura de classes sociais nas mesmas áreas e HIS em áreas bem localizadas sem custo para a Prefeitura. Porém, ao longo da tramitação na Câmara dos Vereadores, a Cota de Solidariedade foi significativamente flexibilizada, e, atualmente, para terrenos acima de $20.000 \mathrm{~m}^{2}$, o construtor poderá doar um terreno em outra área da cidade e até pagar $10 \%$ do valor da gleba do empreendimento ao FUNDURB, com destinação prioritária para moradia social.

De acordo com os entrevistados para o trabalho que dá origem a esse artigo (CHILVARQUER, 2018), a Cota de Solidariedade praticamente ainda não foi implementada para empreendimentos de HIS por ter regulamentação ainda muito recente.

Por fim, aponta-se uma das maiores implementação do MCMV Faixa 1 no país, que é a autorização, decorrente de alteração do desenho geral do programa, de verticalização dos empreendimentos do MCMV Faixa 1. É importante observar que essa alteração no programa é fruto de uma coordenação política entre gestões alinhadas, que culminou em uma importante mudança da regulação federal da política pública.

O Ministério das Cidades e a Caixa Econômica Federal proibiam o uso de elevadores nos empreendimentos do MCMV Faixa 1 em todo o país, limitando o número de andares a quatro por empreendimento. Segundo os entrevistados dessa pesquisa, a vedação do uso de elevadores decorria de uma preocupação com a segurança dos moradores por parte dos órgãos federais, já que os condomínios do MCMV Faixa 1 tem recursos extremamente limitados e a manutenção dos elevadores é considerada cara.

Sobre a permissão da verticalização, apesar de esta ter ocorrido de maneira formal no segundo biênio da gestão Fernando Haddad, ${ }^{50}$ o tema já era discutido desde o começo da implementação do MCMV Faixa 1 na cidade, conforme se observa no relatório de atuação da Diretoria da COHAB de 2011:

Devido às novas especificações foi necessária a revisão das tipologias existentes incluindo o estudo de verticalização dos novos empreendimentos para renda de até 3 salários mínimos. Essa tipologia, com elevador, possibilitará o melhor aproveitamento dos terrenos e a qualidade condominial dos futuros empreendimentos. (COHAB, 2011)

\footnotetext{
${ }^{50}$ Relatório da Diretoria da COHAB em 2016: "Foi assinado Termo de Cooperação Técnica e Parceria entre COHAB-SP, SEHAB - Secretaria Municipal de Habitação e Caixa Econômica Federal - CEF que prevê ações conjuntas para sustentabilidade dos empreendimentos PMCMV com elevadores através de suporte técnico e financeiro da $\mathrm{PMSP} / \mathrm{SEHAB}$ para $\mathrm{CEF}$, para produção e manutenção dos elevadores por 10 anos."
} 
Ao final, a forma jurídica escolhida para viabilizar a instalação dos elevadores nos empreendimentos do MCMV Faixa 1 foi um acordo de cooperação entre COHAB, SEHAB e CEF, em que a Prefeitura ficaria responsável pela manutenção dos elevadores pelo prazo de dez anos nos empreendimentos.

$\mathrm{Na}$ prática, a instalação dos elevadores possibilitou a verticalização dos empreendimentos do MCMV Faixa 1, garantindo prédios com número de apartamentos multiplicado - algo sem dúvida útil em uma cidade como São Paulo, em que o valor da terra é um entrave tão relevante para a execução da política.

\section{CONClUSÃo}

Conforme se explicitou ao longo do artigo, um dos principais desafios da abordagem DPP é encontrar um método que dote as pesquisas sobre uma mesma ação governamental de comparabilidade e, consequentemente, de um possível aprimoramento na intervenção por meio do direito nas políticas públicas.

Ainda que passível de constante aprimoramento no tempo, o quadro de referência para análise jurídica de políticas públicas é uma ferramenta construída buscando sanar essa dificuldade. Para aprimorar o referido método é importante que juristas se lancem na análise de políticas públicas. Esse artigo, fruto de pesquisa realizada na dissertação de mestrado do autor, objetivou "testar" o quadro de referência no exame da implementação do MCMV Faixa 1 no município de São Paulo indicando os ganhos analíticos do método, assim como os desafios na sua análise.

Os achados apresentados nesse artigo pretendiam realizar duas funções primordiais: (i) ajudar a pavimentar um caminho que possibilite um diálogo acadêmico no campo do direito sobre a maior política de provimento habitacional de interesse social da história do Brasil, indicando limites e potencialidades que a intervenção jurídica permite em uma política pública; e (ii) inserir os acadêmicos do direito em um debate multidisciplinar sobre o MCMV Faixa 1 que pode promover reflexões tanto de caráter científico como prático, tendo em vista que os aprendizados do município de São Paulo podem servir de inspiração para outras localidades superarem seus desafios de implementação da política pública. 


\section{REFERÊNCIAS}

AMORE, Caio Santo; SCHIMBO, Lúcia Zanin; RUFINO, Maria Beatriz Cruz (orgs.). Minha casa... e a cidade? Avaliação do programa minha casa minha vida em seis estados brasileiros. Rio de Janeiro: Letra Capital, 2015.

BONDUKI, Nabil. Do Projeto Moradia ao Programa Minha Casa Minha Vida. TD. Teoria e Debate, v. 82, p. 1, 2009.

BONDUKI, Nabil. Os pioneiros da habitação social: Cem anos de política pública no Brasil. São Paulo: Editora Unesp, 2012.

BOULOS, Guilherme. De que lado você está?: reflexões sobre a conjuntura política e urbana no Brasil. São Paulo: Boitempo Editorial, 2015.

BUCCI, Maria Paula Dallari. Fundamentos para uma Teoria Jurídica das Políticas Públicas. São Paulo: Saraiva, 2013.

BUCCI, Maria Paula Dallari. Quadro de referência de uma Política Pública: Primeiras linhas de uma visão jurídico-institucional. In: SMANIO, Gianpaolo Poggio; BERTOLIN, Patrícia Tuma Mantins Bertolin; BRASIL. O Direito na Fronteira das Políticas Públicas. São Paulo: Páginas \& Letras Editora e Gráfica. 2015.

BUCCI, Maria Paula Dallari. Direito e Políticas Públicas: método e aplicações. Revista Estudos Institucionais, v. 5, n. 3, 2019.

BUCCI, Maria Paula Dallari; COUTINHO, Diogo Rosenthal. Arranjos jurídicoinstitucionais da política de inovação tecnológica: uma análise baseada na abordagem de direito e políticas públicas. In: COUTINHO, Diogo R.; FOSS, Maria Carolina; MOUALLEN, Pedro Salomon B. (orgs.). Inovação no Brasil: avanços e desafios jurídicos e institucionais. 1 ed. São Paulo: Editora Edgard Blücher, 2017.

CHILVARQUER, Marcelo. A implementação do Programa Minha Casa, Minha Vida faixa 1 no Município de São Paulo. Dissertação (Mestrado em Direito) Faculdade de Direito, Universidade de São Paulo, São Paulo, 2018.

COUTINHO, Diogo R. O direito nas políticas públicas. Política Pública como Campo Disciplinar (Eduardo Marques e Carlos Aurélio Pimenta de Faria, orgs.). Rio de Janeiro/São Paulo: Ed. Unesp, Ed. Fiocruz, p. 181-200, 2013 a. 
APLICANDO O QUADRO DE REFERÊNCIA PARA ANÁLISE JURÍDICA DE POLÍTICAS PÚBlicAS: A IMPLEMENTAÇÃO DO PROGRAMA MinHA CASA, MinHA VIDA, FAIXA 1, NO MUNICÍPIO DE SÃO PAULO

COUTINHO, Diogo R. Direito, Desenvolvimento e Desigualdade. São Paulo: Saraiva, $2013 b$.

FERREIRA, João Sette Whitaker. Produzir casas ou construir cidades?. Desafios para um novo Brasil urbano, v. 1. São Paulo: Lahab/ Fupam 2012.

FERREIRA, João Sette Whitaker. Minha Casa, Minha Vida: Notas sobre a responsabilidade coletiva de um desastre urbano. Revista Contraste, v. 1, 2014, p. 110-119.

FUNDAÇÃO JOÃO PINHEIRO. Centro de Estatística e Informações. Déficit habitacional no Brasil 2013-2014. Belo Horizonte, 2016.

FURTADO, Fernanda. Recuperação de mais-valias fundiárias urbanas: reunindo os conceitos envolvidos. In: SANTORO, Paula (org.). Gestão social da valorização da terra. São Paulo: Instituto Pólis, 2004.

INSTITUTO ESCOLHAS. MORAR LONGE: o Programa Minha Casa Minha Vida e a expansão das regiões metropolitanas. Disponível em: <http://www.escolhas.org/wp-content/uploads/2019/04/QCML_ RELATORIOFINAL_Site.pdf. janeiro de 2019. Acesso em: 15 dez. 2019.

KLINTOWITZ, Danielle. Por que o Programa Minha Casa Minha Vida só poderia acontecer em um governo petista?. Cadernos Metrópole, v. 18, n. 35, 2016, p. 165190.

KLINTOWITZ, Danielle. Entre a reforma urbana e a reforma imobiliária: a coordenação de interesses na política habitacional brasileira nos anos 2000. 2015. Tese (Doutorado) - Fundação Getúlio Vargas, 2015.

KRAUSE, Cleandro; BALBIM, Renato; NETO, Vicente Correia Lima. Minha Casa Minha Vida, Nosso Crescimento: Onde Fica a Política Habitacional. Texto para Discussão 1853: Instituto de Pesquisa Econômica Aplicada. Brasília/ Rio de Janeiro, Agosto de 2013.

LIS, Lais. Minha Casa Minha Vida completa 10 anos com queda nas contratações. Portal G1, 25 de março de 2019. Disponível em: 
$<$ https:/g1.globo.com/economia/noticia/2019/03/25/minha-casa-minha-vidacompleta-10-anos-com-queda-nas-contratacoes.ghtml>. Acesso em: 30 jul. 2019.

MARQUES, Eduardo; FARIA, Carlos Aurélio. A política pública como campo multidisciplinar (coletânea). São Paulo: Editora Unesp/Rio de Janeiro: Editora Fiocruz. 2013.

MINISTÉRIO DAS CIDADES. Plano Nacional de Habitação. Versão para Debates. Brasília, 2009.

PAIXÃO, Daniela. "Vamos tocar o barco pra frente", diz Lula em SP. UOL Notícias, 27 mar 2009. Disponível em: <http://mais.uol.com.br/view/ 1575mnadmj5c/vamos-tocar-o-barco-pra-frente-diz-lula-em-sp04023168C0C98326?types=A\&>. Acesso em: 10 maio 2019.

RIBEIRO, Silvio Cesar Lima; DANIEL, Marcelo Nakano; ABIKO, Alex. ZEIS maps: Comparing areas to be earmarked exclusively for social housing in São Paulo city. Land Use Policy, v. 58, p. 445-455, 2016.

RODRIGUES, Evaniza Lopes. A estratégia fundiária dos movimentos populares na produção autogestionária de moradia. 2013. Dissertação (mestrado) faculdade de Arquitetura e Urbanismo da Universidade de São Paulo, 2013.

ROLNIK, Raquel. Guerra dos lugares: a colonização da terra e da moradia na era das finanças. São Paulo: Boitempo, 2015.

ROLNIK, Raquel. Ferramentas para avaliação da inserção urbana dos empreendimentos do MCMV. Chamada MCTI/CNPq/MCidades nº 11/2012, nov. 2014.

ROLNIK, Raquel.; SANTORO, Paula. Freire. Zonas Especiais de Interesse Social (ZEIS) em Cidades brasileiras: Trajetória Recente de Implementação de um instrumento de Política Fundiária. Lincoln Institute of Land Policy, 2013.

RUIZ, Isabela, e BUCCI, Maria Paula Dallari. Quadro de problemas de políticas públicas: uma ferramenta para análise jurídico institucional. Dossiê de políticas públicas. Revista Estudos Institucionais, vol. 5, n. 3, 2019.

SANTORO, Paula Freire; BORRELLI, Julia. Os desafios de produzir habitação de interesse social em São Paulo: da reserva de terra no zoneamento às 
APLICANDO O QUADRO DE REFERÊNCIA PARA ANÁLISE JURÍDICA DE POLÍTICAS PÚBlicAS: A IMPLEMENTAÇÃO DO PROGRAMA MinHA CASA, MinHA VIDA, FAIXA 1, NO MUNICÍPIO DE SÃO PAULO

contrapartidas obtidas a partir do desenvolvimento imobiliário ou das ZEIS à Cota de Solidariedade. Anais do Encontro Nacional da Anpur, v. 16, p. 1-19, 2015.

SECRETARIA DE HABITAÇÃO (SEHAB). Plano Municipal de Habitação: A experiência de São Paulo. Elisabete França e Keila Prado Costa (orgs), 2012.

SECRETARIA DE HABITAÇÃO (SEHAB). Plano Municipal de Habitação de São Paulo. Caderno para discussão pública. São Paulo, 2016.

SECRETARIA DE HABITAÇÃO (SEHAB). Balanço de governo. 2013-2016. São Paulo, 2016.

SINGER, André. Os sentidos do lulismo: reforma gradual e pacto conservador. São Paulo: Companhia das Letras, 2012.

TRUBEK, David M.; COUTINHO, Diogo R.; SCHAPIRO, Mario G. Toward a New Law and Development: New State Activism in Brazil and the Challenge for Legal Institutions. In: The World Bank Legal Review: Legal Innovation and Empowerment for Development 2012. 